and other forms that are not tropical, could have reached their present habitat. The range of this Araucaria, although greater by far than that of the other Eutactas, is very definitely limited to a strip of coast in New South Wales between the Bellingen, a small stream about S. lat. $31^{\circ} 40^{\prime}$, and Cape York in Queensland, in nearly $10^{\circ} \mathrm{S}$. lat. It does not approach, therefore, to within nearly a thousand miles of the equator of heat, which is several degrees north of the true equator. They must either have crossed the equator from the south in præeocene times and subsequently become isolated and died out in their northern habitat, or have been originally indigenous to the north and retreated to their present stations. A passage must have been made in either case, for the present distribution of Coniferæ is against the supposition that any identical species could have extended synchronously in lowlands in both hemispheres, widely separated by the equator. If a general lowering of temperature had favoured their passage, the pre-existing tropical vegetation must have altogether died out, and the existing equatorial vegetation would present a comparatively new aspect. The absence of any of the Coniferæ that have ever been met with fossil in the plains of the tropical regions at the present day, and of any existing strictly equatorial plants, such as Gneta among Conifers, in the fossil floras, seems at first sight to show that it does do so and therefore lends some colour to what is at best merely a very crude hypothesis. A simpler supposition than that of a general lowering of temperature in the Tropics, until more facts are forthcoming, is that the passage was effected across high land, some of which may still remain in Sumatra and Java.

The specific identity which is apparent, of this and other Australian forms, with those of our Eocenes, proves that some, at all events, of the at present purely Australian gencra, neither originated norbecame differentiated, as Ben. tham supposed, in Australia. The endemic genera, he says, never spread far out of it, the only exceptions appcaring in the Malay Archipelago, "especially Timor, New Guinea, and Borneo, and a few as far as Southern China." 1 Nothing could speak more eloquently of the path the migrations have taken, than these remnants left upon the road, nor go farther to prove the former connection with our antipodes, which the discovery in 1814 by Brown of 150 European plants, a number since greatly increascd, growing endemically in Australia, first of all I believe suggested to us.

It may not be altogether a useless supposition to hazard, that if, as Saporta supposes, plants originated mainly if not wholly in northern regions, and migrated south, the continents of the southern hemisphere may be actually preserving, as in the present case, our Eocene flora, and have been inhabited in Eocene times by the Jurassic flora which preceded it, or by some intervening flora of which we have now but the scantiest records.

From what has been said the Araucarias are seen to be an archaic type, formerly most widely spread, now dying out and only lingering in restricted areas in the southern hemisphere, whose very specific differentiation was accomplished before the Eocencs began. May its value as food and use as the chief timber tree in the districts it still inhabits preserve it from an accelerated extermination at the hands of man.

J. Starkie Gardner

\section{ON SOME POINTS CONNECTED WITH}

TERRESTRIAL MAGNETISM

THE remarks in NATURE, vol. xxii. p. 169, of Messrs. De La Rue and Müller in connection with their most interesting and important researches on rarefied gases induce me to ask the privilege of stating somewhat more fully than I did on June 17 what I conceive to be the

\footnotetext{
× Bentham, "Flora Australice sis," vo'. vii.
}

position filled by a working hypothesis such as that then mentioned in the science of terrestrial magnetism. Let me begin with the aurora. Here we have a phenomenon which invariably accompanies magnetic storms, on which occasions it occurs simultaneously over a large portion of the globe. Again the recent researches of the abovenamed gentlemen render it very probable that auroral displays do not occur at a very great height, while it is conceivable that they may occur at times at an altitude of a few thousand feet. Here then we have a phenomenon which is intimately connected with sudden changes of the earth's magnetism. To this we may add earth currents as another phenomenon of the same kind, so that we have earth currents and auroral displays invariably associated with magnetic storms, when these are of marked violence. Now what is the nature of this connection? When we examine the formal laws of these associated phenomena we find that these lead us (almost irresistibly, as I think) to conclude that earth currents and auroræ are secondary discharges caused by sudden changes in the earth's magnetism, no matter how these changes are produced. So strong is the evidence of form in this instance that the late eminent magnetician John Allan Broun expressed to me his belief that earth currents and auroræ were connected with magnetic storms in the way above mentioned.

If this be assumed as the most probable working hypothesis, it is natural to take another step. If we have discharges produced in stationary strata by a changing magnet, may we not have discharges produced in moving strata by a constant magnet, and may not the motions and changes of motion produced by the sun in the upper convection currents of the earth give rise to electric phenomena which may explain the changes of terrestrial magnetism? Of course this is only a working hypothesis. Before it can possibly become an established theory we must have obtained from Messrs. De la Rue and Müller and from other observers that full and complete information regarding discharges in rarefied media which they are rapidly affording us, and we must likewise have obtained fuller information than we now possess regarding the directions and velocities of the convection currents in the upper regions of the earth's atmosphere. When this is done, the problem may be regarded as ripe for the mathematical physicist who may proceed with his calculations and either dismiss the hypothesis as untenable or increase the probability of its truth.

But in the meantime we are not ripe for this, and all that we can do is to regard the hypothesis as a working one, and endeavour by its means to elicit new facts regarding the form of the diurnal and other variations of terrestrial magnetism. I submit that in this respect the hypothesis has not been devoid of value. I have by its means been led to derive the fact that certain magnetic diurnal changes lag behind corresponding solar changes, just as meteorological changes would do - a fact which has since been confirmed by Mr. Ellis of the Greenwich observatory. And I may be allowed to anticipate the results of work at which I am now engaged so far as to say that in the short periods which I am now investigating an increase or decrease of solar activity corresponds to an increase or decrease both of magnetical and meteorological activity.

Again, in conjunction with others, I have shown by preliminary discussions the probability of a progress of magnetic phenomena from west to east just as we know there is a progress of meteorological phenomena, only magnetic weather (if I may use the expression) appears to travel faster than meteorological weather. This last appears to me to furnish almost a crucial test in favour of this hypothesis, and through the courtesy of the Kew Committee, the Astronomer Royal, and Mr. Carpmael of Toronto I hope to be able soon to investigate this phenomenon in a more complete manner. 
Finally, I understand that the Kew Committee are about to take in hand the subject of the progress of magnetic weather and to investigate it in a manner peculiarly suitable to an institution possessing relations with numerous self-recording magnetic observatories.

BALFOUR STEWART

\section{NOTES}

THE fund which has been established by the members of the Birmingham Philosophical Society for the endowment of original research already amounts to $700 l$. in donations, and to $70 l$. in annual subscriptions. Out of this a sum of $150 l$. per annum for three years has been yoted to Dr. George Gore, F.R.S., which amount is, in the terms of the grant, placed at his disposal in order that he "may have greater facilities for continuing in Birmingham his original researches." The council of the society proposes to make other grants as soon as the funds will permit. We have already spoken of the enterprise and public spirit of this society in establishing the fund; it is gratifying that they have been able to make a beginning so speedily, and the success of the scheme cannot be doubted. Dr. Gore's address is now the Institute of Scientific Research, No. 67, Broad Street, Birmingham.

WE are glad to hear that Mr. L. Fletcher, M.A., Fellow of University College, Oxford, has been appointed to succeed Prof. Story-Maskelyne as keeper of the Mineral Department of the British Museum. Mr. Fletcher was appointed first assistant in the department a little over three years ago, and the energy and ability with which he discharged the duties of that appointment promise well for the future of the Mineral Department.

We regret to have to announce the death of Mr. Henry Ludlam, which occurred last week from the rupture of a bloodvessel. He had been in failing health for some months, but seemed on the road to recovery when the hæmorrhage occurred. He was well known in the mineralogical world as one of the most assiduous and able of private collectors, and his valuable collection was one of the objects of interest which foreign mineralogists visiting this country wished to consult. $\mathrm{He}$ has carried out his intention, announced several years ago, of bequeathing the collection to the Jermyn Street Museum. This gift will render the collection of this museum second only to that of the British Museum, and will, in fact, render it a formidable rival in the case of some of the rarer and more beantiful minerals. Mr. Ludlam was always willing to allow his mineralogical friends to consult his collection, and also frequently supplied them with specimens for examination.

THE Council of the Society of Arts have awarded medals to the following gentlemen for papers read during the session which is just over:-Major-General H. Y. D. Scott, C.B. F.R.S., for his paper on "Suggestions for Dealing with the Sewage of London;" A. J. Ellis, F.R.S., for his paper on "The History of Musical Pitch;" John Sparkes, for his paper on "Recent Advances in the Production of Lambeth Art Pottery;" Henry B. Wheatley, F.S.A., for his paper on "The History and Art of Bookbinding;" W. Holman Hunt, for his paper on "The Present System of Obtaining Materials in use by Artist Painters, as compared with that of the Old Masters;" Thomas Fletcher, for his paper on "Recent Improvements in Gas Furnaces for Domestic and Laboratory Purposes ;" John C. Morton, for his paper on "The Last Forty Years of Agricultural Experience;" Prof. Heaton, F.C.S., for his paper on "Balmain's Luminous Paint ;" Capt. Abney, R.E., F.R.S., for his paper on "Recent Advances in the Science of Photography."

LORD NORTON has all along protested that he is not unfavourable to the teaching of science in elementary schools, and is evidently hurt at the incredulity with which his protestation is received by those one-sided individuals who persist in judging his intentions by his actions, and not his words. He is evidently of opinion that the only difference between himself and those who would maintain the Code unaltered, is one of method. There are people so benighted as to believe that as science deals with things, it is hopeless to teach it apart from these things; who believe that if you want to make children know what a daisy or a buttercup is like, and to understand its structure, the shortest and most effectual way is to show them the flower and take it to pieces in some sort of systematic way before their eyes. But these people are all wrong. Why should children and teachers put themselves to the trouble of soiling their hands by pulling to pieces nasty weeds, when the thing can be much better done from books? Lord Norton, as we learn from a contemporary, has resolved to triumphantly refute these deluded people, by himself compiling a series of reading lessons in botany, warranted to teach the children of our elementary schools all that it is safe and wholesome for them to know. Evidently modern science and its methods are all wrong; books, after all, are the only instruments of education, and the sooner we make a holocaust of all modern scientific implements and methods the better. Might we suggest to Lord Norton that after he has completed his botanical enterprise he might compile a series of lessons in engineering civil and mining, for the purpose of saving the neophytes in these departments the necessity for spending their time in sooty workshops and stifling mines? In fact there seems no end to the enterprise which Lord Norton is about to "inaugurate ;" if he is able to carry it on to completion, he will probably earn for himself a right to be considered the most remarkable educationist of his time. In the meantime Her Majesty's reply to the address which the Lords were persuaded to adopt is virtually a quiet snub; while in the Commons Mr. Mundella has declared that the Government have no intention of lowering the standard of education in the country. Does not this look rather bad for the success of Lord Norton's projected compilation?

Ir is a tacitly-accepted practice, and one so beneficial to student-readers as to be almost imperative, that writers of original scientific memoirs should, wherever their researches touch upon common ground with those of older workers of standing, give references (at the very least in a decent foot-note) by which the student may be able to turn at once to the ipsissima verba of the possible authorities. We regret to notice an increasing tendency of late to slovenliness in the way of making such references on the part of some of the younger generation of enthusiastic would-be discoverers. Even the Proceedings of the Royal Society itself are not exempt from this modern weed, for in a recent paper we find the following given as references:Phil. Mag., 1850, Pogg. Annalen, 1858, and-for an important deduction from a paper by Clausius-Phil.Mag., I85I. Is it too much to request the writers of Royal Society papers to be at least a little more explicit in their allusions? We cannot suppose that such references are made vague with any sinister purpose.

DR. P. P. C. HoEk of Leiden writes:- "The zoological station of the Netherlands Zoological Society for the summer months of this year is erected in the neighbourhood of Nieuwediep Harbour. The use of the station is free to the members of the Society and to strangers introduced by one of the members. The laboratory is furnished as completely as possible with all the implements-optical and steel. instruments excepted-necessary for anatomical, histological, and embryological researches; it contains also a small collection of books necessary for a preliminary investigation and determination of the animals collected, \&c. Special arrangements of a very simple but practical kind serve to keep alive the collected animals. Smaller and larger 